\title{
Population Dynamics of Bank Voles Predicts Human Puumala Hantavirus Risk
}

\author{
Hussein Khalil, ${ }^{1}$ Frauke Ecke, ${ }^{1,2}$ Magnus Evander, ${ }^{3}$ Göran Bucht, ${ }^{4}$ and Birger Hörnfeldt ${ }^{1}$ \\ ${ }^{1}$ Department of Wildlife, Fish, and Environmental Studies, Swedish University of Agricultural Sciences, 90183 Umeå, Sweden \\ ${ }^{2}$ Department of Aquatic Sciences and Assessment, Swedish University of Agricultural Sciences, P.O. Box 7050, 75007 Uppsala, Sweden \\ ${ }^{3}$ Department of Clinical Microbiology, Virology, Umeå University, 90185 Umeå, Sweden \\ ${ }^{4}$ Swedish Defense Research Agency, CBRN Defence and Security, Umeå, Sweden
}

\begin{abstract}
Predicting risk of zoonotic diseases, i.e., diseases shared by humans and animals, is often complicated by the population ecology of wildlife host(s). We here demonstrate how ecological knowledge of a disease system can be used for early prediction of human risk using Puumala hantavirus (PUUV) in bank voles (Myodes glareolus), which causes Nephropathia epidemica (NE) in humans, as a model system. Bank vole populations at northern latitudes exhibit multiannual fluctuations in density and spatial distribution, a phenomenon that has been studied extensively. Nevertheless, existing studies predict NE incidence only a few months before an outbreak. We used a time series on cyclic bank vole population density (1972-2013), their PUUV infection rates (1979-1986; 2003-2013), and NE incidence in Sweden (1990-2013). Depending on the relationship between vole density and infection prevalence (proportion of infected animals), either overall density of bank voles or the density of infected bank voles may be used to predict seasonal NE incidence. The density and spatial distribution of voles at density minima of a population cycle contribute to the early warning of NE risk later at its cyclic peak. When bank voles remain relatively widespread in the landscape during cyclic minima, PUUV can spread from a high baseline during a cycle, culminating in high prevalence in bank voles and potentially high NE risk during peak densities.
\end{abstract}

Keywords: Bank vole, Disease dynamics, Epidemiology, Hantavirus, Landscape, Nephropathia epidemica, Puumala virus, Sweden

\section{INTRODUCTION}

The emergence and re-emergence of virulent human pathogens over the past two decades (Kilpatrick and Randolph 2012) increased alertness to the global burden of infectious diseases originating in wildlife. Changes in scale

Published online: July 15, 2019

Correspondence to: Hussein Khalil, e-mail: Hussein.khalil@liverpool.ac.uk and distribution of such diseases were typified by recent high-profile outbreaks of Ebola virus in West Africa (Spengler et al. 2016) and the introduction of West Nile virus in North America (Jones et al. 2008).

For many vector-borne and zoonotic diseases, multiple species with different life histories and population dynamics are involved in the sequence of transmission events that lead to human infections. Hosts and vectors commonly show discernible seasonal (Altizer et al. 2006) 
and annual or multiannual variation (Ostfeld et al. 2006) in abundance and infection rates. Often, changes in host abundance are accompanied by behavioral changes driven by factors inherent to host populations, e.g., life history and demographic traits (Olsson et al. 2003a; Fichet-Calvet et al. 2014). To mitigate zoonotic risk, a system-level understanding of the ecology of the disease system-constituted by host, vector, and pathogen-is pertinent (Mills and Childs 1998).

Rodents are important hosts of zoonotic diseases (Han et al. 2015). Globally, rodent-borne zoonotic pathogens cause a plethora of diseases, including hemorrhagic fevers caused by hantaviruses and arenaviruses. Many rodent populations exhibit great spatial and temporal fluctuations in density (Krebs and Myers 1974; Davis et al. 2005). These fluctuations include annual (Singleton et al. 2001) and multiannual population cycles, the latter typical of northern latitudes (Krebs 1996). Over the course of a multiannual cycle, small mammal density can vary by several orders of magnitude (Krebs 1978; Hörnfeldt 1978; Hansson and Henttonen 1985; Hörnfeldt 1994). Fluctuations in abundance are often accompanied by changes in spatial distribution (e.g., Khalil et al. 2014b; Hörnfeldt et al. 2006; Carver et al. 2015), leading to pronounced changes in zoonotic risk over local spatial and short temporal scales (Ostfeld et al. 2005).

In Europe, rodents are responsible for thousands of annual cases of hemorrhagic fever with renal syndrome (HFRS; Vaheri et al. 2013), caused by two pathogenic species of the genus Hantavirus. In central and eastern Europe, yellow-necked and wood mice (Apodemus spp.) are carriers of Dobrava hantavirus (Nemirov et al. 1999), which causes most cases of hemorrhagic fever in the region. In contrast, bank voles (Myodes glareolus) carry Puumala hantavirus (PUUV) (Brummer-Korvenkontio et al. 1980), which causes a mild form of HFRS in humans known as Nephropathia epidemica (NE). PUUV is responsible for NE in Russia, Central and Western Europe, Finland, and northern Scandinavia (Olsson et al. 2010). Humans get infected upon the inhalation of aerosolized viral particles (Vapalahti et al. 2010; Vaheri et al. 2013).

The transmission of PUUV in bank voles is horizontal via direct contact or through the environment (Hardestam et al. 2008). Infection and shedding of viral particles in bank voles are chronic (Voutilainen et al. 2015). Viral RNA is secreted and excreted in saliva, urine, and feces. Viral shedding reaches its peak within a month after infection (Hardestam et al. 2008), yet remains relatively high after- ward (Voutilainen et al. 2015). Infected females transfer maternal antibodies to their offspring, providing protection for up to 3 months (Kallio et al. 2010). The relationship between host and infected host densities is described by infection prevalence, i.e., proportion of infected animals, and depends on how transmission rates respond to changes in host density and demography (Begon et al. 2002; Davis et al. 2005). At elevated densities, contact rates or duration of contacts between infected and susceptible individuals may increase, resulting in a higher rate of transmission (reviewed in Khalil et al. 2014a for hantaviruses). However, transmission may be frequency dependent (McCallum et al. 2001), implying that contact rate among susceptible and infectious individuals remains constant regardless of changes in density. In such a scenario, the density of infected animals may increase with overall host density, but prevalence does not. Realistically, transmission does not necessarily conform exactly to density or frequency dependence. It can take alternative forms or be appropriately described through network models of contact (e.g., Olinky and Stone 2004). Nevertheless, if prevalence in bank voles increases with density, an increase in density would result in an exponential increase in the number of infected animals (Davis et al. 2005).

The number of annual cases of NE is closely linked to the abundance of bank voles in Finland (Kallio et al. 2009), Sweden (Niklasson et al. 1995; Olsson et al. 2009), and Central and Western Europe (Tersago et al. 2010; Reil et al. 2015). In Fennoscandia, most cases occur during winter, when infected bank voles infest human dwellings (Olsson et al. 2003a). In temperate Europe, NE risk can be predicted 2 years in advance based on weather conditions that promote high seed production from broad-leaved trees such as oak and beech. This "masting" phenomenon leads to subsequent bank vole population outbreaks (Tersago et al. 2009). At northern latitudes, small mammal cycles have intrigued ecologists for many decades, and a large body of literature is dedicated to understanding and explaining them (Krebs and Myers 1974; Hörnfeldt 1978, 1994, 2004; Hansson and Henttonen 1985; Hörnfeldt et al. 2005; Cornulier et al. 2013; Korpela et al. 2014; Magnusson et al. 2015a; Pöysä et al. 2016). However, despite extensive knowledge on multiannual bank vole cycles, existing studies predict NE incidence only a few months before an outbreak (Kallio et al. 2009; Olsson et al. 2009; Khalil et al. 2014b).

Here, we use a long time series on cyclic bank vole populations, their PUUV infection rates, and NE incidence 
in northern Sweden to infer seasonal and multiannual transmission dynamics within bank vole populations. We demonstrate how ecological and epidemiological aspects of a disease system can be combined for early warning of NE risk. We further discuss based on the seasonal relationship between bank vole density and their infection prevalence, whether seasonal infection risk in humans is better predicted by overall bank vole density or by the density of infected animals.

\section{Methods}

\section{Bank Vole Data}

Bank vole density data were available in spring and autumn 1972-2013 through the ongoing Swedish National Environmental Monitoring Program for small rodents near the city of Umeå in northern Sweden $\left(64^{\circ} \mathrm{N}, 20^{\circ} \mathrm{E}\right)$ (Hörnfeldt 1994). Snap trapping of small mammals takes place twice a year within a $100 \times 100 \mathrm{~km}$ area in 58 permanent and systematically placed 1-ha plots at least $2.5 \mathrm{~km}$ apart. There are ten trapping stations per 1-ha plot, each station with five traps within a circle of a $1 \mathrm{~m}$ radius. Spring trapping and autumn trapping occur in late May and late September, respectively, for three consecutive nights. The total effort per plot in a session is 150 trap nights (see Hörnfeldt 1978, 1994, 2004 for further details). For spring and autumn seasons, we calculated an index of bank vole density as the overall number of bank voles trapped per 100 trap nights, hereafter referred to as bank vole density. The bank vole time series spanned 12 complete cycles in population density (numbered I-XII; see Magnusson et al. 2015a) and exhibited marked differences in amplitude and peak numbers during the 43year period (Fig. 1a) (Hörnfeldt 1994, 2004). A vole cycle generally comprises $3-4$ years and is characterized by the following phases in density: increase, peak, decrease, and low (Hörnfeldt 1994).

\section{Ethics Statement}

Trapping of animals was approved by the Swedish Environmental Protection Agency (latest permission: NV01124-15) and the Animal Ethics Committee in Umea (latest permissions: Dnr A 61-11 and A121-11), and all applicable institutional and national guidelines for the use of animals were followed.

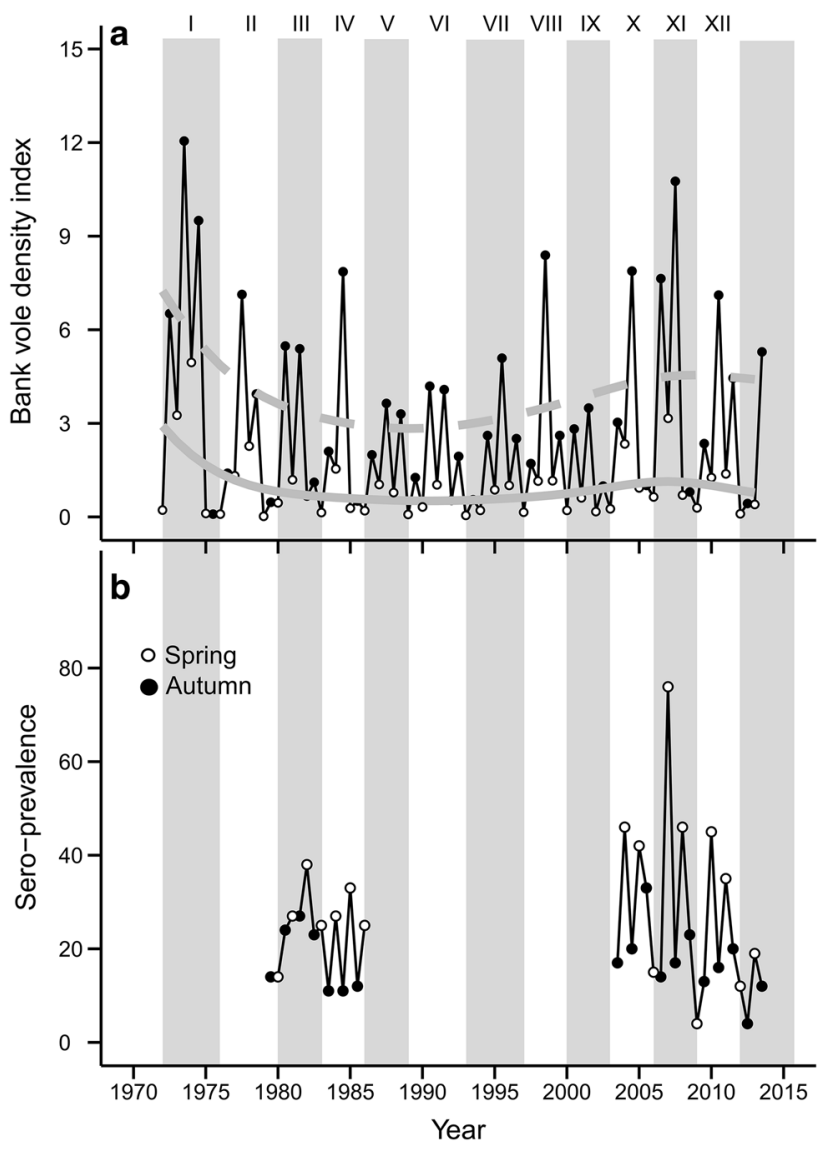

Figure 1. a Bank vole density index (number of trapped individuals per 100 trap nights) in 1972-2013 and b Puumala virus (PUUV) seroprevalence in spring (open circles) and autumn (filled circles). Data on PUUV seroprevalence are from autumn 1979 to spring 1986 and autumn 2003 to autumn 2013. No infection data were available in 1971-1978 and 1987-2002. Alternate shadings indicate different cycles, numbered I-XII. The gray lines in a represent the fitted GAM models (solid for spring and dashed for autumn).

\section{PUUV Infection Data in Bank Voles}

Data on PUUV infection in bank voles were available in autumn 1979-1986 and 2003-2013 and spring 1980-1986 and 2004-2013 (see further Magnusson et al. 2015b; Khalil et al. 2016). We analyzed lung samples from bank voles by enzyme-linked immunosorbent assay (ELISA) to detect anti-PUUV IgG antibodies and identify seropositive individuals (Lindkvist et al. 2008; Khalil et al. 2016). The detection threshold in the PUUV IgG ELISA was determined by analyzing 32 sera, previously confirmed PUUV negative by immunofluorescence assay. The assay threshold was determined by counting the mean optical density value of these PUUV-negative samples +3 standard deviations. Seropositive bank voles weighing $<14.4 \mathrm{~g}$ may carry maternal antibodies (Kallio et al. 2006; Voutilainen et al. 
2012) and were excluded from further analyses as their status may not reflect genuine infection ( $n=348$ in 19791986; $n=902$ in 2003-2013). PUUV infection in bank voles is chronic and infected individuals shed the virus throughout their life (Voutilainen et al. 2015), so we considered seropositive individuals infected.

Subsequent analyses of available PUUV infection data were based on 2064 and 4294 bank voles in 1979-1986 and 2003-2013, respectively. We calculated prevalence for spring and autumn seasons (see above) for which infection data were available as the percentage of infected animals trapped in that season (number of infected bank voles/ overall number of bank voles) $\times 100$. Data on bank vole abundance are available through the national environmental monitoring Web site [In Swedish]: https://www.slu. se/institutioner/vilt-fisk-miljo/miljoanalys/miljoovervaknin g-av-smagnagare/.

\section{NE Incidence Data}

NE has been a notifiable disease in Sweden since 1989, i.e., $\mathrm{NE}$ cases are diagnosed by accredited clinical microbiology laboratories and must be reported to the Public Health Agency of Sweden. Human incidence data for the four northernmost counties, where more than $90 \%$ of NE cases occur (Olsson et al. 2003a), were available from the Public Health Agency of Sweden Web site (https://www.folkhals omyndigheten.se/ [In Swedish]). The data were available at county level, and NE incidence (no. cases per 100,000 inhabitants) was divided into two periods: spring-summer period (April-September, hereon referred to as summer) and autumn-winter period (October-March, hereon referred to as winter and the year for that season refers to the year in October, when the season started). The time periods for incidence were chosen such that bank vole density and infected bank vole density in spring and autumn would be used to predict NE incidence over two six-month periods (summer and winter). Since spring trapping and autumn trapping of bank voles are separated by 4 months only (late May to late September), we included April and May in summer incidence. To investigate the potential bias in predictions arising from our classification of summer and winter periods, we compared the results from the original classification with those using a different classification, with summer incidence defined as May-October or JuneNovember and winter as September-February or November-April. The results were qualitatively the same (SI Table 1). Hence, we persisted with the original periods: summer being April-September and winter being OctoberMarch. In subsequent analyses, we used NE incidence data in 1990-2013, as preliminary analysis suggested that the first year of reporting, 1989, was a negative outlier with NE incidence being much lower than expected given bank vole density in the same year (Khalil et al. 2014b).

\section{Statistical Analyses}

Long-Term Trends in Bank Vole Density

All statistical analyses were performed in R statistical software ( $\mathrm{R}$ Core Team 2016) using base $\mathrm{R}$ except when otherwise stated.

To describe the long-term changes in bank vole populations in 1972-2013, we fitted generalized additive models (GAM) with year as the explanatory variable to spring and autumn vole densities using "mgcv" package (Wood 2011). We used GAMs (Zuur et al. 2009), adjusted for over-dispersion and non-integer values through a quasi-Poisson error distribution. Because the observations in the time series were not independent, we used an autocorrelation function, with an order (lag) defined by parameter $p$. We included lags up to three years $(p=3)$, the typical length of a bank vole population cycle (Hörnfeldt 1994), to account for previous population density in spring and autumn (for spring and autumn models, respectively). We compared the models with different time lags (Hefley et al. 2017) using an adjusted form of the Akaike Information Criterion (AIC), qAIC, because we used quasiPoisson models (Burnham and Anderson 2002; Ver Hoef and Boveng 2007). If two or more models differed by two or less qAIC units, we chose the simplest. The fitted GAM model for each season was:

$$
\ln \left(\mu_{i, j}\right)=f(\text { Year })_{j}+\sum_{p=1}^{3} \emptyset_{i, j} \times D_{i, j-p}
$$

where $\mu_{i, j}$ is the expected value of the bank vole density $(D)$ during the $i$ th season of the $j$ th year, $f(\text { Year })_{j}$ is the effect for the $j$ th year from a smoothing function over the years of the study, and $\emptyset_{i, j}$ is the effect of bank vole density from the $p$ th previous season $i$ (lag effect).

We followed the same procedure for the subsequent GAM models. We also checked for temporal confounding between the basis vector for the smoothed parameter: year, and the lags we included in the model. Concurvity is the nonparametric analog of multicollinearity and may lead to 
Table 1. Sensitivity Analysis for Nephropathia epidemica Classification of Summer and Winter Seasons.

\begin{tabular}{llc}
\hline NE summer & Bank vole density (\%) & Infected bank vole density (\%) \\
\hline Spring & & 87 \\
April-September & 88 & 88 \\
May-October & 92 & 91 \\
June-November & 92 & 45 \\
Autumn & 77 & 49 \\
October-March & 80 & 38 \\
September-February & 70 & 3 \\
November-April & & \\
\hline
\end{tabular}

We evaluated how the proportion of explained variation (GLM, pseudo $R^{2}$ ) in seasonal Nephropathia epidemica incidence (NE) changes with the classification of summer and winter time periods.

underestimation of the variance model parameters and thus type 1 errors (Hefley et al. 2017). The models for NE incidence and bank vole density all had concurvity scores $<0.1$ and thus did not show temporal confounding. For all models, we checked for autocorrelation and nonlinear patterns in the residuals.

\section{Bank Vole Density and Infection Prevalence}

PUUV prevalence in bank voles was a proportion, and hence, for both spring and autumn seasons, we fitted a generalized linear model with binomial error distribution and a logit link function using PUUV prevalence in bank voles as the dependent variable. Vole density during the same season and that during the previous season were the explanatory variables, to test for both direct and delayed density dependence (Niklasson et al. 1995). The model was the following:

$$
\operatorname{logit}(P)=\beta_{0} \times D_{i}+\emptyset_{i} \times D_{i-1}
$$

where $P$ is the probability of a bank vole being PUUV positive, $\beta_{0}$ is the effect of $(D)$ bank vole density in season $i$, and $\emptyset_{i}$ is the effect of bank vole density $(D)$ in the previous season $(i-1)$.

We also calculated PUUV infection prevalence in bank voles in spring and autumn between two distinct time periods with different bank vole densities (cf. Khalil et al. 2016), spanning a total of five population cycles. During the earlier period: 1979-1986 (cycles III and IV, $n_{\text {bank voles }}=2412$ ), bank vole densities were lower than during the latter period (see above): 2003-2013 (cycles XXII, $\left.n_{\text {bank voles }}=5196\right)$. We also used $F$-ratio tests to compare the variance in prevalence in 1979-1986 with variance in prevalence in 2003-2013.

\section{Explaining Seasonal NE Incidence in Humans}

We investigated long-term changes in NE incidence in summer and winter in 1990-2013. We fitted GAM models with year as explanatory variable using a quasi-Poisson error structure and log link function and included an autocorrelation process to the residuals, with an order (lag) of up to 3 years. The lag represented NE incidence in the same season (summer or winter) in the previous 3 years:

$$
\ln \left(\mu_{i, j}\right)=f(\text { Year })_{j}+\sum_{p=1}^{3} \emptyset_{i, j} \times I_{i, j-p}
$$

where $\mu_{i, j}$ is the expected value of NE incidence $(I)$ during the $i$ th season of the $j$ th year, $f(\text { Year })_{j}$ is the effect for the $j$ th year from a smoothing function over the years of the study, and $\emptyset_{i, j}$ is the effect of NE incidence from the $p$ th previous season $i$ (lag effect).

To evaluate whether overall host density or density of infected animals better predicts seasonal NE incidence, we compared using qAIC two models that used either overall density of bank voles or density of infected voles during the period 2003-2013. We studied NE incidence models for summer and winter separately, resulting in a total of four generalized linear models (GLM) with a quasi-Poisson error distribution and log link function. The models explaining $\mathrm{NE}$ incidence in each season were:

$$
\ln \left(\mu_{i}\right)=\beta_{0} \times D_{i}
$$

where $\mu_{i}$ is the expected value of NE incidence in season $i$ and $\beta_{0}$ is the effect of vole density $(D)$ in season $i$ and

$$
\ln \left(\mu_{i}\right)=\beta_{0} \times \text { Dpos }_{i}
$$


where $\mu_{i}$ is the expected value of NE incidence in season $i$ and $\beta_{0}$ is the effect of density of infected bank voles (Dpos) in season $i$.

\section{Early Forecast of NE Risk}

In the first spring of the vole cycle, densities are normally at a 3-4-year minimum, and a high reproductive output during the ensuing summer signals the beginning of a new cycle (Hörnfeldt 1994). In rare exceptions, this increase phase extends into a second year, as in 1980 when the initial increase in 1979 started from a very low density and yielded little numerical increase in absolute numbers. The population thus remained at very low density in autumn (Fig. 1a). We used bank vole density in spring of the increase phase (sensu Hörnfeldt 1994)—from the year when the population also attained a density of $>1$ bank vole per 100 trap nights in autumn (in 1980, 1983, 2003, 2006, and 2009) - to predict the maximum density of infected voles reached during that cycle (five cycles: cycles: III-IV in 1979-1986 and X-XII in 2003-2013). We fitted a linear regression model and evaluated its predictive performance using predictive residual sum of squares (PRESS), despite the small sample size $(n=5)$. PRESS value is calculated by removing one observation from the data, fitting to the model to the remaining observations, and then using the regression function to predict the excluded value. The procedure then is repeated for all observations $(n=5)$, and subsequently a predictive $R^{2}$ is calculated based on the PRESS values (Frost 2013). The predictive $R^{2}$ indicates how good the model is in predicting left-out data points. The linear regression model was:

$$
\pi_{c}=\beta_{0} \times D_{c}
$$

where $\pi_{c}$ is the expected value of maximum bank vole density in a vole population cycle $(c)$ and $\beta_{0}$ is the effect of bank vole density $(D)$ at the beginning of that cycle. We also correlated the proportion of the 58 1-ha plots occupied in spring of the increase phase as defined above with density of infected bank voles in spring of the following year, a peak year.

\section{RESULTS}

Bank vole density decreased during the 1980s and 1990s and then increased during the 2000s in both spring and autumn (Fig. 1a). Based on qAIC comparison (SI Table 2), the best model for each season included a temporal auto- correlation function with a two-year lag (GAM: $F_{39}=16.98 ; p<0.001$ for spring, $F_{39}=7.645 ; p<0.001$ for autumn).

Overall PUUV prevalence in bank voles in spring 1980-1986 was $27.5 \%$ (mean annual prevalence $=27 \%$, standard error $(\mathrm{SE})=2.8)$ and was $47 \%$ in spring between 2004 and 2013 (mean annual prevalence $=34 \%, \mathrm{SE}=6.8$ ) (Fig. 1b). In autumn, overall prevalence was $19 \%$ in 1979 1986 (mean annual prevalence $=17 \%, \mathrm{SE}=2.6)$ compared to $16.5 \%$ in $2003-2013$ (mean annual prevalence $=17 \%$, $\mathrm{SE}=2.4$ ). Also, variance in prevalence in spring in 20042013 was higher than variance in 1980-1986, but not in autumn $\left(F_{6,9}\right.$ ratio $=0.12, p<0.05$ for spring, $F_{6,10}$ ratio $=1.32, p=0.66$ for autumn).

Spring PUUV prevalence in bank voles was dependent on bank vole density during current spring and previous autumn (pseudo $R^{2}=83 \%, p<0.01$ for both predictors) in the five cycles between 1980 and 1986 (III and IV) and 2004-2013 (X, XI, XII). Autumn prevalence, however, was not significantly related to current or previous bank vole density $(p=0.93)$.

Between 1990 and 2013, NE incidence generally mirrored the changes in bank vole density (Fig. 2, GAM: $F_{20.4}=16.79 ; \quad p<0.001 \quad$ for summer, $\quad F_{21.5}=24.96$; $p<0.001$ for winter). The best model for summer and winter incidence included a temporal autocorrelation term with a two-year lag (SI Table 2). The temporal autocorrelation in NE incidence was likely due to its dependence on cyclic vole densities, and thus NE incidence displayed a cyclic pattern itself.

Overall bank vole density and density of infected voles in spring predicted NE incidence well in summer (Fig. 3a, b), explaining $88 \%$ (Odds Ratio $(\mathrm{OR})=2.42$; $\mathrm{CI}=1.95$ 3.01; $d f=8 ; p<0.001)$ and $87 \%(\mathrm{OR}=3.68$; $\mathrm{CI}=2.66-$ 5.11; $d f=8 ; p<0.001$ ) of the variation (pseudo- $R^{2}$ ), respectively, and $\Delta$ qAIC was $<2$. Likewise, in winter, bank vole density in autumn significantly predicted NE incidence and explained 77\% (OR = 1.38; CI = 1.20-1.60; $d f=9, p<0.01$, Fig. $3 c$ ) of the variation, but density of infected bank voles was borderline nonsignificant with $\Delta \mathrm{qAIC}>10$ and only explained $47 \%(\mathrm{OR}=4.23$; $\mathrm{CI}=$ $1.12-16.00 ; d f=9, p=0.06)$ of the variation in NE winter incidence (Fig. 3d). Interestingly, the increase in NE incidence with bank vole density appeared almost linear in summer but exponential in winter (Fig. 3a, c).

Bank vole density in the spring of the increase phase could predict the maximum attained density of infected voles-typically 18 months later-during the same cycle 
Table 2. Modeling Nephropathia epidemica Incidence and Bank Vole Density Over Time Through Generalized Additive Models (GAM).

\begin{tabular}{|c|c|}
\hline Model & $\Delta \mathrm{qAIC}$ \\
\hline \multirow{2}{*}{\multicolumn{2}{|c|}{$\begin{array}{l}\text { Generalized additive model (GAM) bank vole density over time } \\
\text { Spring }\end{array}$}} \\
\hline & \\
\hline No autocorrelation function & 17.5 \\
\hline Bank vole density 1 year earlier & 19.5 \\
\hline Bank vole density 1 and 2 years earlier & - \\
\hline Bank vole density up to 3 years earlier & 1.6 \\
\hline \multicolumn{2}{|l|}{ Autumn } \\
\hline No autocorrelation function & 25.4 \\
\hline Bank vole density 1 year earlier & 24.5 \\
\hline Bank vole density 1 and 2 years earlier & 1.7 \\
\hline Bank vole density up to 3 years earlier & - \\
\hline \multicolumn{2}{|c|}{$\begin{array}{l}\text { Generalized additive model (GAM) Nephropathia epidemica inci } \\
\text { dence over time }\end{array}$} \\
\hline \multicolumn{2}{|l|}{ Summer } \\
\hline No autocorrelation function & 11.4 \\
\hline Incidence 1 year earlier & 12.1 \\
\hline Incidence 1 and 2 years earlier & - \\
\hline Incidence up to 3 years earlier & 1.6 \\
\hline \multicolumn{2}{|l|}{ Winter } \\
\hline No autocorrelation function & 7.2 \\
\hline Incidence 1 year earlier & 11.5 \\
\hline Incidence 1 and 2 years earlier & - \\
\hline Incidence up to 3 years earlier & 7.9 \\
\hline
\end{tabular}

The choice of autocorrelation function for each model and season was based on qAIC comparisons (c.f. methods in the manuscript). We chose the model with the lowest qAIC value. If two or more models differed by less than two qAIC units, we chose the simplest mode.

$(t=5.4, d f=3, p=0.01)$. The predictive $R^{2}$, calculated from PRESS, was $80 \%$. However, this result needs to be interpreted with caution, given that we only had data for five vole population cycles. Similarly, bank vole occupancy of the landscape, expressed as proportion of occupied sampling plots during spring of the increase phase of the cycle, was strongly correlated with density of infected bank voles the following spring (Fig. 4, Pearson $r=0.96, t=4.3$, $d f=3, p<0.05)$. However, this relationship also reflects the influence of overall bank vole density, as density and spatial distribution of bank voles in the landscape are strongly correlated (Khalil et al. 2014b). The highest NE incidence in each vole population cycle reflected initial overall bank vole density and maximum attained density of infected animals (Fig. 5).

\section{DIscussion}

Overall bank vole density and the density of infected bank voles in spring predicted NE incidence in summer accurately, whereas overall bank vole density in autumn, but not density of infected animals, was a good nonlinear predictor of NE incidence in winter. Our results also suggest that the highest density of infected bank voles in a population cycle, contributing to peak NE risk, can be predicted at the beginning of that cycle, approx. 18 months earlier.

\section{Long-Term Trends in Bank Vole Density}

Previous studies reported dramatic declines of field vole (Microtus agrestis) and gray-sided vole (Myodes rufocanus) populations during the past three decades (Hörnfeldt 2004; Cornulier et al. 2013; Magnusson et al. 2015a). Bank vole populations also declined, but the decline was partly reversed, and peak density of population cycles increased during the 2000s (Fig. 1a). In Central Finland, similar changes in bank vole dynamics occurred, where dampened changes in density between 1995 and 1998 reverted to multiannual high-density fluctuations after 1999 (Kallio et al. 2009). These synchronous and similar patterns in Sweden and Finland suggest a form of regional influence of winter weather on population dynamics of small mammals, e.g., of field voles (Microtus agrestis) (Hörnfeldt 2004) and Norwegian lemmings (Lemmus lemmus) (Kausrud et al. 2008). Reduced competition from declining sympatric vole species and relaxed predation from declining predators may have benefitted bank vole populations (Magnusson et al. 2015a; Khalil et al. 2016), possibly facilitating the recent recovery of bank vole population.

\section{Bank Vole Density and Infection Prevalence}

A positive correlation between prevalence and host density was reported in the PUUV-host system (Olsson et al. 2003a; Voutilainen et al. 2012) —and in other rodent-borne zoonoses, such as in plague (Davis et al. 2004). Here, we found that spring PUUV prevalence was dependent on autumn, i.e., "initial," vole density and vole survival through the course of winter, reflected by vole density in spring. Recently, Voutilainen et al. (2016) reported that most PUUV infections in bank voles occur during winter, which is consistent with our findings here and suggests accelerated transmission. During winter, bank voles would have lost the protection provided by maternal antibodies 

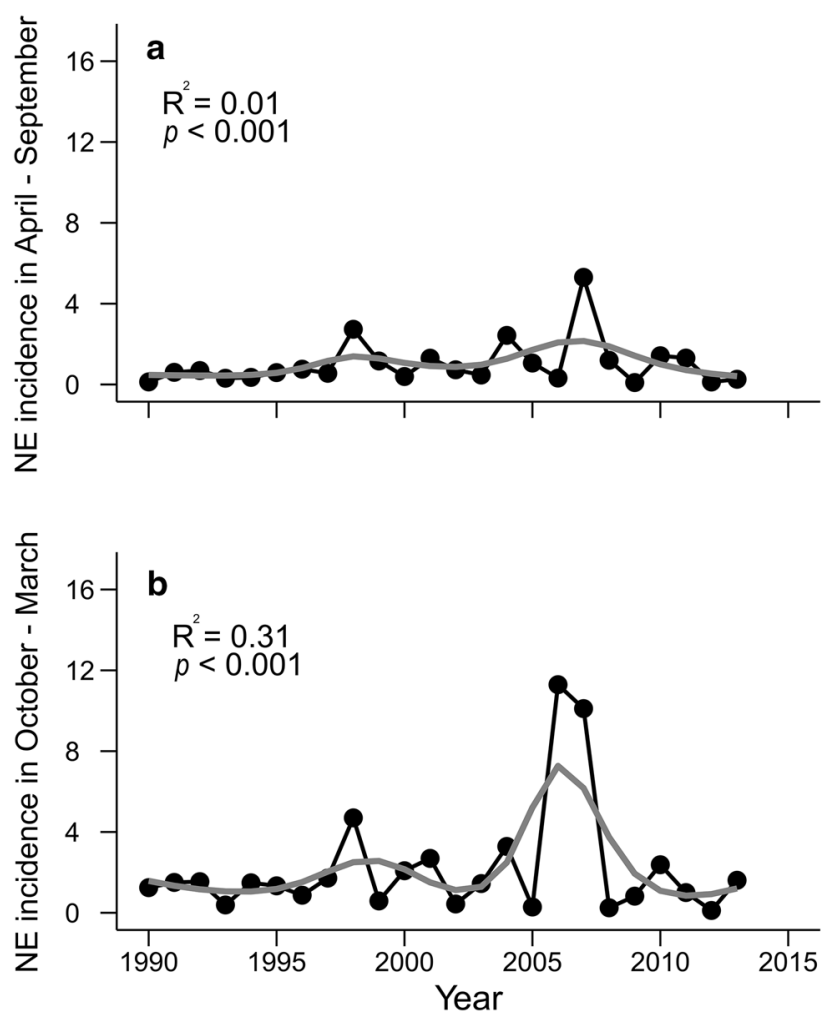

Figure 2. Nephropathia epidemica (NE) incidence in northern Sweden (no. cases/100,000 inhabitants) in a spring-summer (April-September) and b autumn-winter (October-March) 19902013. The gray line represents the fitted GAM model.

(Kallio et al. 2010). Additionally, they lose territoriality and tend to aggregate (Ylönen and Viitala 1985), which likely increases their contact rates. Virus survival in the environment may be enhanced due to lower temperatures and high moisture levels (Kallio et al. 2006). Consequently, the rate at which susceptible bank voles are exposed to PUUV particles in the environment during winter probably increases.

PUUV prevalence and overall density of bank voles in spring were higher and fluctuated with greater amplitude in 2004-2013 compared to 1980-1986 (Fig. 1). The low spring densities between 1980 and 1986 indicate that bank vole populations declined too rapidly during winter and thus failed to sustain high levels of PUUV transmission. In such a scenario, the PUUV in bank vole system would be in disequilibrium, as high autumn density after reproduction leads to a brief increase in transmission rate, only to be offset soon after by a swift decline in host density (Luis et al. 2015). In 2004-2013, higher densities in spring suggest that PUUV transmission remained high during winter, leading to elevated PUUV prevalence (Fig. 1b).
In autumn, we found no evidence for a relationship between the density of bank voles and their infection prevalence. The influx of newborn voles during the reproductive season probably masked any increase in PUUV transmission rate with density (Niklasson et al. 1995; Lehmer et al. 2012; Roche et al. 2012). We have previously found that infection probability in autumn increases with bank vole weight, a surrogate for age (Khalil et al. 2016). An increase in infection probability with host age is typical for horizontally transmitted pathogens, including hantaviruses (Kuenzi et al. 2001; Olsson et al. 2002). In autumn, $41 \%$ of trapped bank voles weighed $<$ $17 \mathrm{~g}$ and were probably younger than 12 weeks of age (Kruczek 1986), compared to $1 \%$ in spring. This demographic bias toward younger individuals, resulting in a "juvenile dilution effect," may be responsible for the idiosyncratic relationship between density and prevalence in autumn, as voles born in the same season have not yet been exposed to PUUV or are temporarily immune due to maternal antibodies.

The 58 trapping plots in our $100 \times 100 \mathrm{~km}$ study area provide landscape-level estimates of host density and PUUV prevalence. However, the data provide less insight on short-term temporal patterns in PUUV transmission, since sampling was only twice a year, essentially for population monitoring purposes (Hörnfeldt 1978, 1994, 2004). For example, the observed decoupling of host abundance and prevalence in autumn was most likely transient and observed through a snapshot of the relationship between density and prevalence at a time of high vole population turnover. Studies of monthly or bimonthly changes in PUUV prevalence are better suited to investigate how short-term demographic and density changes influence transmission and prevalence (e.g., Kallio et al. 2009; Voutilainen et al. 2016).

\section{Explaining Seasonal NE Incidence in Humans}

The changes in NE incidence reflected corresponding patterns in vole density and prevalence (Figs. 1, 2). The observed increase in winter NE incidence with autumn bank vole density (Fig. 3c) is compatible with an increase in winter PUUV prevalence in bank voles. At higher bank vole densities, accelerated PUUV transmission in late autumn and winter (Voutilainen et al. 2016) would likely lead to an increase in the density of infected individuals, exacerbating human risk. Bank voles share nests (Glorvigen et al. 2012), and previously immune voles lose maternal antibodies with 

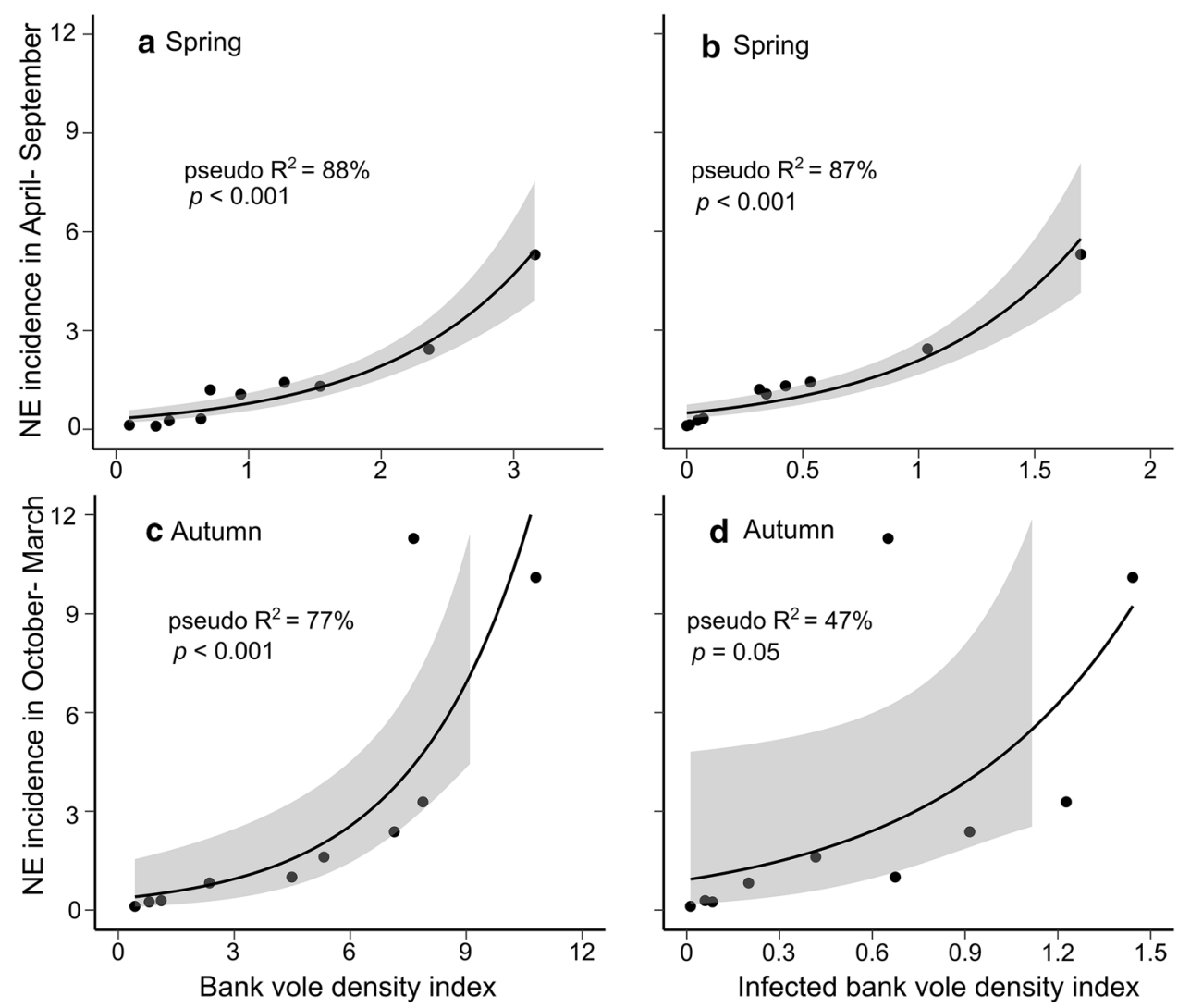

Figure 3. Explaining Nephropathia epidemica (NE) incidence in northern Sweden (no. cases/100,000 inhabitants), in a, b April-September and c, $\mathbf{d}$ October-March using overall density of bank voles $(\mathbf{a}, \mathbf{c})$ and density of infected bank voles $(\mathbf{b}, \mathbf{d})$ in spring and autumn. The black lines correspond to fitted generalized linear models with quasi-Poisson error distribution, and the gray shaded area represents standard error around fitted line.

increased age (Kallio et al. 2006), possibly explaining accelerated transmission in winter. In spring, however, bank vole populations consisted mainly of overwintered individuals, and we suspect that the rate of PUUV transmission had already stabilized, which is supported by the almost linear relationship between spring bank vole density and summer NE incidence (Fig. 3a). Had PUUV transmission rates and recruitment of infected animals remained high during spring, we would expect a nonlinear increase in NE incidence. The relationship between spring bank vole density and summer NE incidence would then be similar to the observed relationship between autumn bank vole density and NE incidence in winter (Fig. 3c).

Ultimately, given the relationship between bank vole density and prevalence in spring, both overall density of bank voles and that of infected bank voles were satisfactory predictors of NE risk in summer. Thus, density of bank voles in spring can be used to predict human incidence in summer without any knowledge on spring infection rates, a result reported earlier (Kallio et al. 2009). In winter, bank vole density in autumn was a good nonlinear predictor of human risk, in contrast to density of infected voles, which we expect to increase rapidly as PUUV transmission accelerates during winter.

Assessing risk of zoonotic diseases that originate in wildlife entails disentangling what is often a complex ecological system. PUUV is a directly transmitted pathogen, and its transmission within host populations and to humans does not involve a vector. The relative simplicity of this pathogen-host system compared to vector-borne zoonoses such as Lyme disease (Ostfeld et al. 2006) makes it a good model system to link host density and infection dynamics to human risk. Nevertheless, factors other than bank vole density and infection rates play a role in $\mathrm{NE}$ epidemiology. For example, seasonal differences in human behavior and vole infestation of human dwellings are important (Olsson et al. 2003b). Winter weather, especially rain-on-snow phenomenon (Khalil et al. 2014b), may trigger bank vole movement into human dwellings to seek shelter from cold. Future studies ought to test these 
hypotheses by linking vole infestation and human exposure to PUUV to environmental variables such as habitat and temperature.

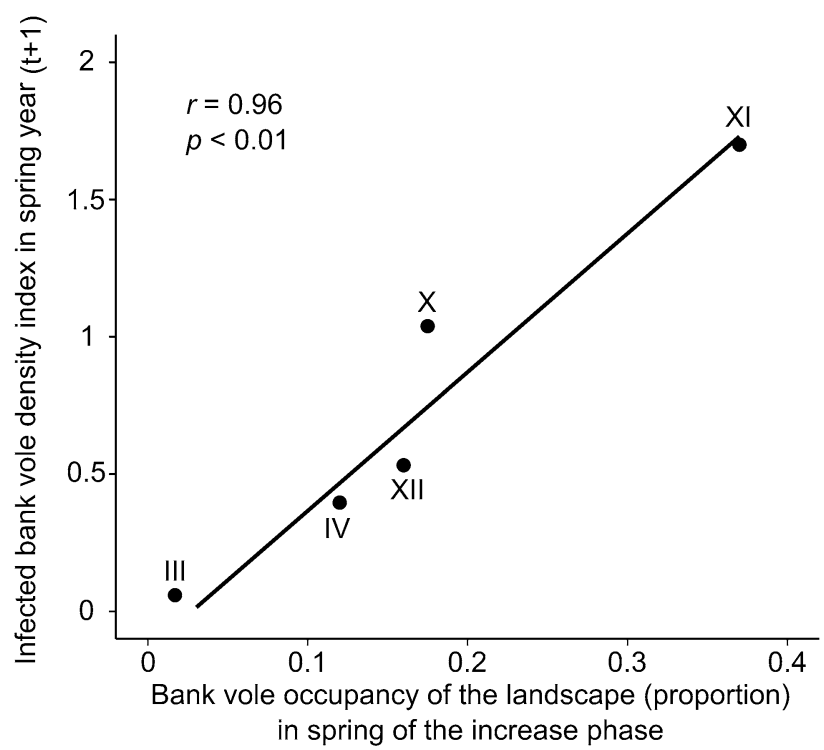

Figure 4. Dependence of infected bank vole density in spring year $t+1$, in the five cycles with infection data (III, IV, X, XI, XII), on bank vole occupancy of the landscape (proportion) in spring of the increase phase, when average autumn density had reached $>1$ individual per 100 trap nights. $r$ is Pearson's correlation coefficient.

\section{Early Forecast of NE Risk}

The density and landscape distribution of bank voles at low density (increase phase) at the start of population cycles can contribute to the early warning of NE risk. Bank vole landscape distribution during the increase phase of a population cycle in spring was correlated with the density of infected animals 1 year later, in spring of the peak phase (Fig. 4). While density of bank voles during the increase phase predicts the maximum density of infected bank voles reached anytime during that cycle. We only had five bank vole population cycles to base these predictions upon, which may have contributed to the high predictive performance of the model. Ongoing monitoring of bank vole populations will enable further validation of its predictive capacity.

When host density drops below a certain threshold, the pathogen may go locally extinct and infection rates take longer to build from that low level (Luis et al. 2015). In cyclic populations with predictable changes in host population trends, density minima determine the starting point of pathogen proliferation. Relatively higher host densities during those minima can act as a springboard for pathogen transmission and culminate in higher risk in the near future, when high reproductive output leads to peak density of infected animals. Our result indicates that the highest

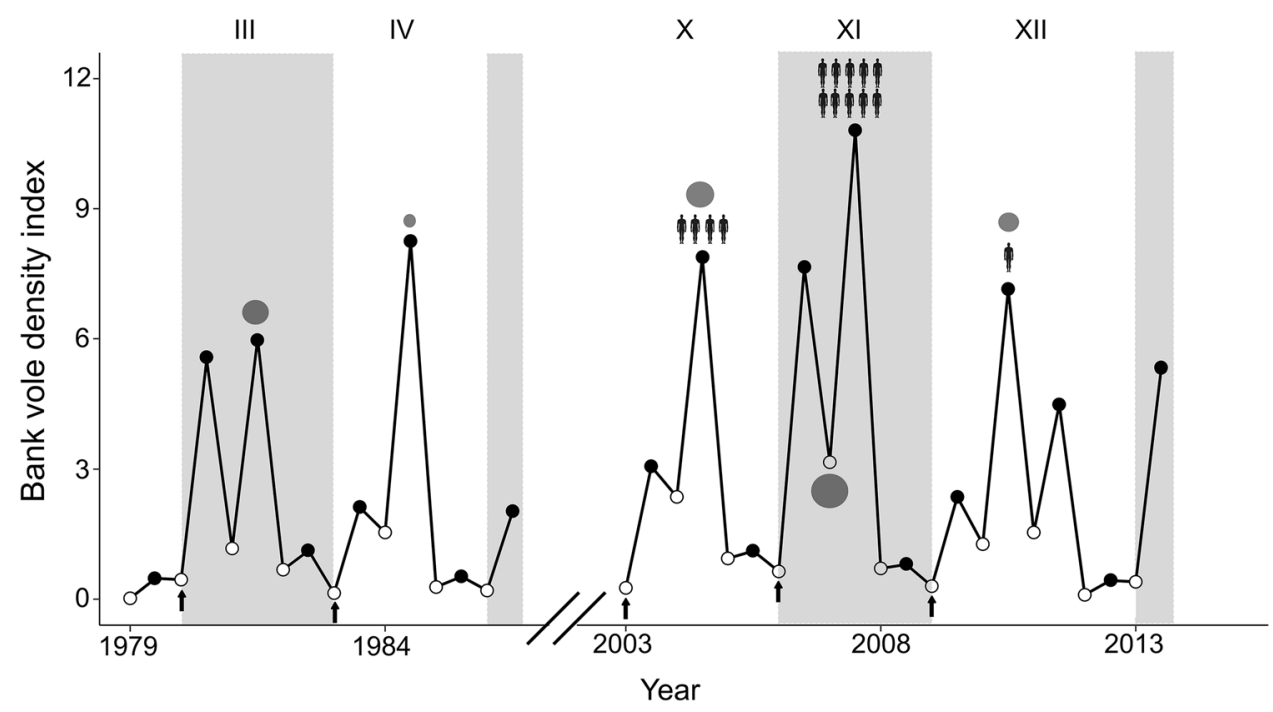

Figure 5. Bank vole density (number of trapped individuals per 100 trap nights) in different cycles (every other cycle is shaded) in 1979-1986 and 2003-2013 in spring (open circles) and autumn (filled circles). The size of the gray circles is proportional to the maximum density of infected voles and positioned to indicate when that density was reached in a cycle $(133,72,113,161,88$, infected bank voles in 1981, 1984, 2004, 2007, 2010, respectively). Arrows indicate springs when we forecast the maximum density of infected bank voles, typically 18 months earlier. Human infection data were available for 2003-2013 ( $n=3$ cycles; see methods), and the number of human silhouettes is proportional to annual incidence of Nephropathia epidemica in northern Sweden (no. cases/100,000 inhabitants) in July to following June in the year with maximum density index of infected bank voles (466, 1278, 128 cases in 2004, 2007, 2010, respectively). 
density of infected voles then contributes to maximum NE incidence during a given cycle (Fig. 5).

\section{CONCLUSIONS}

Elucidating the relationship between host abundance and its infection prevalence on the one hand and disease incidence on the other can guide data collection for risk assessment, e.g., when to sample from host populations and what parameters are most suitable to obtain for risk prediction. In spring, when overall bank vole density and infection prevalence were positively related, bank vole density can be used to predict human risk in summer. In autumn, bank vole density and infection prevalence were decoupled, and human risk in winter was nonlinearly related to bank vole density, suggesting an accelerated transmission among bank voles in winter. To forecast the potential of an NE outbreak during a given vole cycle, bank vole density at the beginning of that cycle, i.e., 18 months earlier, may be used.

\section{ACKNOWLEDGEMENTS}

Open access funding provided by Swedish University of Agricultural Sciences. This study was funded by the Swedish Research Council Formas (Grant No. 221-20121568). The study was also supported by the Swedish Natural Science Research Council, Stiftelsen Seth M. Kempes Minne, Olle och Signhild Engkvists Stiftelser, the Swedish Environmental Protection Agency, and Helge Ax.son Johnsons Stiftelse.

\section{Compliance with Ethical Standards}

CONFLICT OF INTEREST All authors declare that there is no conflict of interest.

\section{Open Access}

This article is distributed under the terms of the Creative Commons Attribution 4.0 International License (http://creativecommons.org/licenses/by/4.0/), which permits unrestricted use, distribution, and reproduction in any medium, provided you give appropriate credit to the original author(s) and the source, provide a link to the Creative Commons license, and indicate if changes were made.

\section{REFERENCES}

Altizer S, Dobson A, Hosseini P, Hudson P, Pascual M, Rohani P (2006) Seasonality and the dynamics of infectious diseases. Ecology Letters 9(4):467-484. https://doi.org/10.1111/j.14610248.2005.00879.x

Begon M, Bennett M, Bowers RG, French NP, Hazel SM, Turner J (2002) A clarification of transmission terms in host-microparasite models: numbers, densities and areas. Epidemiology and Infection 129(1):147-153

Brummer-Korvenkontio M, Vaheri A, Hovi T, von Bonsdorff $\mathrm{CH}$, Vuorimies J, Manni T, et al. (1980) Nephropathia epidemica: detection of antigen in bank voles and serologic diagnosis of human infection. Journal of Infectious Diseases 141(2):131-134. https://doi.org/10.1093/infdis/141.2.131

Burnham KP, Anderson DR (2002) Model selection and multimodel inference: a practical information-theoretic approach, 2nd ed., New York: Springer

Carver S, Mills JN, Parmenter CA, Parmenter RR, Richardson KS, Harris RI, et al. (2015) Toward a mechanistic understanding of environmentally forced zoonotic disease emergence: Sin Nombre Hantavirus. BioScience 65(7):651-666. https://doi.org/10.1093/ biosci/biv047

Cornulier T, Yoccoz NG, Bretagnolle V, Brommer JE, Butet A, Ecke F, et al. (2013) Europe-wide dampening of population cycles in keystone herbivores. Science 340(6128):63-66. https:// doi.org/10.1126/science.1228992

Davis S, Calvet E, Leirs H (2005) Fluctuating rodent populations and risk to humans from rodent-borne zoonoses. Vector-Borne and Zoonotic Diseases 5(4):305-314

Davis S, Begon M, De Bruyn L, Ageyev VS, Klassovskiy NL, Pole SB, et al. (2004) Predictive thresholds for Plague in Kazakhstan. Science 304(5671):736-738

Fichet-Calvet E, Becker-Ziaja B, Koivogui L, Günther S (2014) Lassa serology in natural populations of rodents and horizontal transmission. Vector-Borne and Zoonotic Diseases 14(9):665674. https://doi.org/10.1089/vbz.2013.1484

Frost J (2013) Multiple regression analysis: use adjusted R-squared and predicted R-squared to include the correct number of variables. Minitab Blog 13:06

Glorvigen P, Bjørnstad ON, Andreassen HP, Ims RA (2012) Settlement in empty versus occupied habitats: an experimental study on bank voles. Population Ecology 54(1):55-63. https:// doi.org/10.1007/s10144-011-0295-0

Han BA, Schmidt JP, Bowden SE, Drake JM (2015) Rodent reservoirs of future zoonotic diseases. Proceedings of the $\mathrm{Na}$ tional Academy of Sciences 112(22):7039-7044

Hansson L, Henttonen H (1985) Gradients in density variations of small rodents: the importance of latitude and snow cover. Oecologia 67(3):394-402. https://doi.org/10.1007/BF00384946

Hardestam J, Karlsson M, Falk KI, Olsson GE, Klingström J, Lundkvist $\AA$ (2008) Puumala hantavirus excretion kinetics in bank voles (Myodes Glareolus). Emerging Infectious Diseases 14(8):1209-1215. https://doi.org/10.3201/eid1408.080221

Hefley TJ, Broms KM, Brost BM, Buderman FE, Kay SL, Scharf HR, et al. (2017) The basis function approach for modeling autocorrelation in ecological data. Ecology 98(3):632-646

Hörnfeldt B (1978) Synchronous population fluctuations in voles, small game, owls, and Tularemia in Northern Sweden. Oecologia 32(2):141-152. https://doi.org/10.1007/BF00366068 
Hörnfeldt B (1994) Delayed density dependence as a determinant of vole cycles. Ecology 75(3):791-806. https://doi.org/10.2307/ 1941735

Hörnfeldt B (2004) Long-term decline in numbers of cyclic voles in boreal Sweden: analysis and presentation of hypotheses. Oikos 107(2):376-392. https://doi.org/10.1111/j.0030-1299.2004.133 48.x

Hörnfeldt B, Hipkiss T, Eklund U (2005) Fading out of vole and predator cycles? Proceedings of the Royal Society of London B: Biological Sciences 272(1576):2045-2049. https://doi.org/ 10.1098/rspb.2005.3141

Hörnfeldt B, Christensen P, Sandström P, Ecke F (2006) Longterm decline and local extinction of Clethrionomys rufocanus in boreal Sweden. Landscape Ecology 21:1135-1150

Jones KE, Patel NG, Levy MA, Storeygard A, Balk D, Gittleman JL, Daszak P (2008) Global trends in emerging infectious diseases. Nature 451(7181):990-993. https://doi.org/10.1038/ nature 06536

Kallio ER, Poikonen A, Vaheri A, Vapalahti O, Henttonen H, Koskela E, Mappes T (2006) Maternal antibodies postpone hantavirus infection and enhance individual breeding success. Proceedings of the Royal Society B: Biological Sciences 273(1602):2771-2776. https://doi.org/10.1098/rspb.2006.3645

Kallio ER, Begon M, Henttonen H, Koskela E, Mappes T, Vaheri A, Vapalahti O (2009) Cyclic hantavirus epidemics in humans-predicted by rodent host dynamics. Epidemics 1(2):101107. https://doi.org/10.1016/j.epidem.2009.03.002

Kallio ER, Begon M, Henttonen H, Koskela E, Mappes T, Vaheri A, Vapalahti O (2010) Hantavirus infections in fluctuating host populations: the role of maternal antibodies. Proceedings of the Royal Society B: Biological Sciences 277:3783-3791

Kausrud KL, Mysterud A, Steen H, Vik JO, Østbye E, Cazelles B, et al. (2008) Linking climate change to lemming cycles. Nature 456(7218):93-97. https://doi.org/10.1038/nature07442

Khalil H, Ecke F, Evander M, Magnusson M, Hörnfeldt B (2016) Declining ecosystem health and the dilution effect. Scientific Reports 6:31314. https://doi.org/10.1038/srep31314

Khalil H, Hörnfeldt B, Evander M, Magnusson M, Olsson GO, Ecke F (2014) Dynamics and drivers of hantavirus prevalence in rodent populations. Vector-Borne \& Zoonotic Diseases 14(8):537-551. https://doi.org/10.1089/vbz.2013.1562

Khalil H, Olsson GE, Ecke F, Evander M, Hjertqvist M, Magnusson M, Ottosson-Löfvenius M, Hörnfeldt B (2014) The importance of bank vole density and rainy winters in predicting Nephropathia epidemica incidence in Northern Sweden. PLoS ONE. https://doi.org/10.1371/journal.pone.0111663

Kilpatrick AM, Randolph SE (2012) Drivers, dynamics, and control of emerging vector-borne zoonotic diseases. The Lancet 380(9857):1946-1955. https://doi.org/10.1016/S0140-6736(12)6 $1151-9$

Korpela K, Helle P, Henttonen H, Korpimäki E, Koskela E, Ovaskainen O, et al. (2014) Predator-vole interactions in northern Europe: the role of small mustelids revised. Proceedings of the Royal Society B: Biological Sciences 281:20142119

Krebs CJ (1996) Population cycles revisited. Journal of Mammalogy 77(1):8-24. https://doi.org/10.2307/1382705

Krebs CJ (1978) A review of the chitty hypothesis of population regulation. Canadian Journal of Zoology 56(12):2463-2480. https://doi.org/10.1139/z78-335

Krebs CJ, Myers JH (1974) Population cycles in small mammals. Advances in Ecological Research 8:267-399
Kruczek M (1986) Seasonal effects on sexual maturation of male bank voles (Clethrionomys glareolus). Journal of Reproduction and Fertility 76(1):83-89

Kuenzi AJ, Douglass RJ, White D, Bond CW, Mills JN (2001) Antibody to Sin Nombre Virus in rodents associated with peridomestic habitats in West Central Montana. American Journal of Tropical Medicine and Hygiene 64:137-146

Lehmer EM, Korb J, Bombaci S, McLean N, Ghachu J, Hart L, et al. (2012) The interplay of plant and animal disease in a changing landscape: the role of sudden aspen decline in moderating Sin Nombre Virus prevalence in natural deer mouse populations. EcoHealth 9(2):205-216. https://doi.org/10.1007/ s10393-012-0765-7

Lindkvist M, Näslund J, Ahlm C, Bucht G (2008) Cross-reactive and serospecific epitopes of nucleocapsid proteins of three Hantaviruses: prospects for new diagnostic tools. Virus Research 137(1):97-105. https://doi.org/10.1016/j.virusres.2008.06.003

Luis AD, Douglass RJ, Mills JN, Bjørnstad ON (2015) Environmental fluctuations lead to predictability in Sin Nombre Hantavirus outbreaks. Ecology 96(6):1691-1701

Magnusson M, Hörnfeldt B, Ecke F (2015) Evidence for different drivers behind long-term decline and depression of density in cyclic voles. Population Ecology 57(4):569-580. https://doi.org/ 10.1007/s10144-015-0512-3

Magnusson M, Ecke F, Khalil H, Olsson GE, Evander M, Niklasson B, Hörnfeldt B (2015) Spatial and temporal variation of hantavirus bank vole infection in managed forest landscapes. Ecosphere 6(9):1-18. https://doi.org/10.1890/ES15-00039.1

McCallum H, Barlow N, Hone J (2001) How should pathogen transmission be modelled. Trends in Ecology and Evolution 16(6):295-300

Mills JN, Childs JE (1998) Ecologic studies of rodent reservoirs: their relevance for human health. Emerging Infectious Diseases $4(4): 529$

Nemirov K, Vapalahti O, Lundkvist Å, Vasilenko V, Golovljova I, Plyusnina A, et al. (1999) Isolation and characterization of Dobrava Hantavirus carried by the striped field mouse (Apodemus Agrarius) in Estonia. Journal of General Virology 80(2):371-379. https://doi.org/10.1099/0022-1317-80-2-371

Niklasson B, Hörnfeldt B, Lundkvist Å, Björsten S, LeDuc J (1995) Temporal dynamics of Puumala Virus antibody prevalence in voles and of Nephropathia epidemica incidence in humans. The American Journal of Tropical Medicine and Hygiene 53(2):134140

Olinky R, Stone L (2004) Unexpected epidemic thresholds in heterogeneous networks: the role of disease transmission. Physical Review E 70:030902

Olsson GE, Ahlm C, Elgh F, Verlemyr AC, White N, Juto P, Palo RT (2003) Hantavirus antibody occurrence in bank voles (Clethrionomys glareolus) during a vole population cycle. Journal of Wildife Diseases 39(2):299-305

Olsson GE, Dalerum F, Hörnfeldt B, Elgh F, Palo TR, Juto P, Ahlm C (2003) Human hantavirus infections, Sweden. Emerging Infectious Diseases 9(11):1395-1401. https://doi.org/10.3201/ eid0911.030275

Olsson GE, Hjertqvist M, Lundkvist ̊̊, Hörnfeldt B (2009) Predicting high risk for human hantavirus infections, Sweden. Emerging Infectious Diseases 15(1):104-106. https://doi.org/ 10.3201/eid1501.080502

Olsson GE, Leirs H, Henttonen H (2010) Hantaviruses and their hosts in Europe: reservoirs here and there, but not everywhere? 
Vector-Borne and Zoonotic Diseases 10(6):549-561. https:// doi.org/10.1089/vbz.2009.0138

Olsson GE, White N, Ahlm C, Elgh F, Verlemyr AC, Juto P, Palo RT (2002) Demographic factors associated with hantavirus infection in bank voles (Clethrionomys glareolus). Emerging Infectious Diseases 8(9):924-929

Ostfeld RS, Glass G, Keesing F (2005) Spatial epidemiology: an emerging (or re-emerging) discipline. Trends in Ecology \& Evolution 20(6):328-336. https://doi.org/10.1016/j.tree.2005. 03.009

Ostfeld RS, Canham CD, Oggenfuss K, Winchcombe RJ, Keesing F (2006) Climate, deer, rodents, and acorns as determinants of variation in lyme-disease risk. PLoS Biology 4(6):e145

Pöysä H, Jalava K, Paasivaara A (2016) Generalist predator, cyclic voles and cavity nests: testing the alternative prey hypothesis. Oecologia 182:1083-1093

R Core Team (2016) R: a language and environment for statistical computing. $R$ Foundation for Statistical Computing, Vienna, Austria. URL https://www.R-project.org/.

Reil D, Imholt C, Eccard JA, Jacob J (2015) Beech fructification and bank vole population dynamics-combined analyses of promoters of human Puumala Virus infections in Germany. PLoS ONE 10(7):e0134124. https://doi.org/10.1371/journal. pone. 0134124

Roche B, Dobson AP, Guégan JF, Rohani P (2012) Linking community and disease ecology: the impact of biodiversity on pathogen transmission. Philosophical Transactions of the Royal Society of London B: Biological Sciences 367(1604):2807-2813

Singleton G, Krebs CJ, Davis S, Chambers L, Brown P (2001) Reproductive changes in fluctuating house mouse populations in Southeastern Australia. Proceedings of the Royal Society B: Biological Sciences 268(1477):1741-1748. https://doi.org/ 10.1098/rspb.2001.1638

Spengler JR, Ervin ED, Towner JS, Rollin PE, Nichol ST (2016) Perspectives on West Africa Ebola Virus Disease Outbreak, 2013-2016. Emerging Infectious Diseases 22(6):956-963. https:// doi.org/10.3201/eid2206.160021

Tersago K, Verhagen R, Servais A, Heyman P, Ducoffre G, Leirs H (2009) Hantavirus disease (Nephropathia Epidemica) in Belgium: effects of tree seed production and climate. Epidemiology and Infection 137(2):250. https://doi.org/10.1017/S09502 68808000940
Tersago K, Verhagen R, Vapalahti O, Heyman P, Ducoffre G, Leirs H (2010) Hantavirus outbreak in western Europe: reservoir host infection dynamics related to human disease patterns. Epidemiology and Infection 139(3):381-390. https://doi.org/ $10.1017 /$ S0950268810000956

Vaheri A, Henttonen H, Voutilainen L, Mustonen J, Sironen T, Vapalahti O (2013) Hantavirus infections in Europe and their impact on public health: hantavirus infections in Europe. Reviews in Medical Virology 23(1):35-49. https://doi.org/10.1002/ rmv.1722

Vapalahti K, Virtala AM, Vaheir A, Vapalahti O (2010) Casecontrol study on Puumala virus infection: smoking is a risk factor. Epidemiology and Infection 138(4):576-584

Ver Hoef JM, Boveng PL (2007) Quasi-poisson versus negative binomial regression: How should we model overdispersed count data? Ecology 88(11):2766-2772

Voutilainen L, Kallio ER, Niemimaa J, Vapalahti O, Henttonen H (2016) Temporal dynamics of puumala hantavirus infection in cyclic populations of bank voles. Scientific Reports 6:21323. https://doi.org/10.1038/srep21323

Voutilainen L, Savola S, Kallio ER, Laakkonen J, Vaheri A, Vapalahti O, Henttonen $\mathrm{H}$ (2012) Environmental change and disease dynamics: effects of intensive forest management on Puumala hantavirus infection in boreal bank vole populations. PLoS ONE 7(6):e39452. https://doi.org/10.1371/journal. pone.0039452

Voutilainen L, Sironen T, Tonteri E, Bäck AT, Razzauti M, Karlsson M, et al. (2015) Life-long shedding of Puumala hantavirus in wild bank voles (Myodes glareolus). Journal of General Virology 96:1238-1247

Wood S (2011) Fast Stable restricted maximum likelihood and marginal likelihood estimation of semiparametric generalized linear models. Journal of the Royal Statistical Society (B) 73(1):336

Ylönen H, Viitala J (1985) Social organization of an enclosed winter population of the bank vole Clethrionomys glareolus. Annales Zoologici Fennici 22:353-358

Zuur AF, Ieno EN, Walker NJ, Saveliev AA, Smith GM (2009) Additive modelling. Mixed effects models and extensions in ecology, New York: Springer 